\title{
Article \\ Miniature Coil for Wireless Power and Data Transfer through Aluminum ${ }^{+}$
}

\author{
Juan M. Romero-Arguello ${ }^{1, *}$, Anh-Vu Pham ${ }^{1}$, Christopher S. Gardner ${ }^{2}$ and Brad T. Funsten ${ }^{2}$ \\ 1 Department of Electrical and Computer Engineering, University of California Davis, Davis, CA 95616, USA; \\ ahpham@ucdavis.edu \\ 2 Lawrence Livermore National Laboratory, Livermore, CA 95616, USA; gardner36@1lnl.gov (C.S.G.); \\ funsten1@llnl.gov (B.T.F.) \\ * Correspondence: jmro@ucdavis.edu \\ + This journal article is an extended version of the paper "Miniature Coil Design for Through Metal Wireless \\ Power Transfer" presented in the 2021 IEEE Wireless Power Transfer Conference, San Diego, CA, USA, 1-4 \\ June 2021.
}

check for

updates

Citation: Romero-Arguello, J.M.;

Pham, A.-V.; Gardner, C.S.; Funsten, B.T. Miniature Coil for Wireless Power and Data Transfer through Aluminum. Sensors 2021, 21, 7573. https://doi.org/10.3390/s21227573

Academic Editors: Jenshan Lin and J.-C. Chiao

Received: 19 October 2021

Accepted: 11 November 2021

Published: 15 November 2021

Publisher's Note: MDPI stays neutral with regard to jurisdictional claims in published maps and institutional affiliations.

Copyright: (c) 2021 by the authors. Licensee MDPI, Basel, Switzerland. This article is an open access article distributed under the terms and conditions of the Creative Commons Attribution (CC BY) license (https:/ / creativecommons.org/licenses/by/ $4.0 /)$.

\begin{abstract}
This paper presents the design and development of miniature coils for wireless power and data transfer through metal. Our coil has a total size of $15 \mathrm{~mm} \times 13 \mathrm{~mm} \times 6 \mathrm{~mm}$. Experimental results demonstrate that we can harvest $440 \mathrm{~mW}$ through a $1 \mathrm{~mm}$-thick aluminum plate. Aluminum and stainless-steel barriers of different thicknesses were used to characterize coil performance. Using a pair of the designed coils, we have developed a through-metal communication system to successfully transfer data through a $1 \mathrm{~mm}$-thick aluminum plate. A maximum data rate of $100 \mathrm{bps}$ was achieved using only harvested power. To the best of our knowledge, this is the first report that demonstrates power and data transfer through aluminum using miniature coils.
\end{abstract}

Keywords: inductive coupling; wireless power; inductive power transfer

\section{Introduction}

Wireless power and data transfer through metal enables a new set of applications in critical fields such as sensing of temperature and pressure behind sealed metal containers in aircraft fuselages, vehicle armor, and isolated chambers [1-4]. Inductive coupling is key to non-contact or wireless power and data transfer through metal surfaces $[5,6]$. Research in the area of wireless power and data transfer through metal has been mainly focused on large coils for power transfer [7,8]. In [9], authors employed a coil with an outer diameter of $30 \mathrm{~mm}$ enclosing a metal pipe to transfer $30 \mu \mathrm{W}$ through stainless steel (1.6-mm). In [4], a solenoid coil of $234 \mathrm{~mm} \times 63 \mathrm{~mm} \times 61 \mathrm{~mm}$ was used with an even larger core to transfer $1.2 \mathrm{~W}$ at $10 \%$ efficiency through stainless steel (10-mm). In [10-12], a helical stacked coil of $49 \mathrm{~mm}$ outer diameter and $50 \mathrm{~mm}$ height demonstrated power transfer of $5 \mathrm{~W}$ at $9 \%$ efficiency through aluminum $(3.1 \mathrm{~mm})$. Only [9] has partially demonstrated power and data transfer through metal using the same coil structure, but information on the coil size and data rate were not available. In general, the size of a coil used for wireless power transfer through metal ranges between $30 \mathrm{~mm}$ to $400 \mathrm{~mm}$ [4,9-13]. The large coil size poses a limitation for certain applications [14].

This journal article is an extended version of the paper "Miniature Coil Design for Through Metal Wireless Power Transfer" presented in the 2021 IEEE Wireless Power Transfer Conference, San Diego, CA, USA, 1-4 June 2021 [15]. In our conference paper, we demonstrated the optimization of a wire gauge for building a planar circular geometry coil. The planar circular geometry coils were used in an inductive link to demonstrate $100 \mathrm{~mW}$ harvested power through a $1 \mathrm{~mm}$-thick aluminum plate without any data communication.

In this paper, we present the development of a miniature coil for through metal power and data transfer using inductive coupling. Our new coil has a very small size of 
$15 \mathrm{~mm} \times 13 \mathrm{~mm} \times 6 \mathrm{~mm}$. Our developed coil deviates from the traditional flat circular or square geometries [16] to maximize the effect of its ferrite core to obtain superior harvested power in through metal scenarios. To fabricate the coil, 24 AWG copper wire was tightly wound around a rectangular ferrite core. The winding covered the entire core, with more than 25 turns per layer and four layers in total. Two identical coils placed on both side of a $1 \mathrm{~mm}$-thick aluminum plate were used to form an inductive link for energy transfer. The experimental results demonstrate that $440 \mathrm{~mW}$ was harvested through the $1 \mathrm{~mm}$ aluminum plate using our miniature coils. The coil can operate up to $2 \mathrm{kHz}$ for aluminum and stainless steel metal barriers. We report the measured harvested power and efficiency of the new coil for stainless steel and aluminum barriers with different thicknesses. We developed a through-metal communication system where the same pair of coils is used for both energy transfer and wireless communications. Furthermore, the inside communication subsystem (inside a metal box) only uses harvested power for operation. We have demonstrated a successful bidirectional communication at a minimum of 100 bps using $75 \mathrm{~mW}$ harvested energy for the inside subsystem through a $1 \mathrm{~mm}$ aluminum barrier. Communication through aluminum is significant since is a light-weight material.

\section{Miniature Coil}

The miniature coil design is based on the principle of maximizing the interaction between the coil winding and its core [17]. To maximize this interaction, the coil is designed by winding a copper wire around a ferrite core, instead of the traditional planar coil geometries in our previous work [15]. Using this type of geometry, the flux path is reduced to about $50 \%$ of the coil length to minimize the overall size of the required coil [18]. As a result, we are able to design a very compact coil with very high inductance and quality factor even at a very low operating frequency.

Figure 1 shows the diagram and photograph of the fabricated coils. The coil is made using insulated 24 AWG copper wire, 25 turns per layer, and 4 layers in total. The core usable area is $13 \mathrm{~mm} \times 13 \mathrm{~mm}$ and made of Material 43 from Fair-Rite with $\mu_{i}=800$ [19]. The use of ferrite will help increase the self-inductance and coupling factor of the coils, hence the mutual inductance. The characteristics of the designed coil are shown in Table 1.
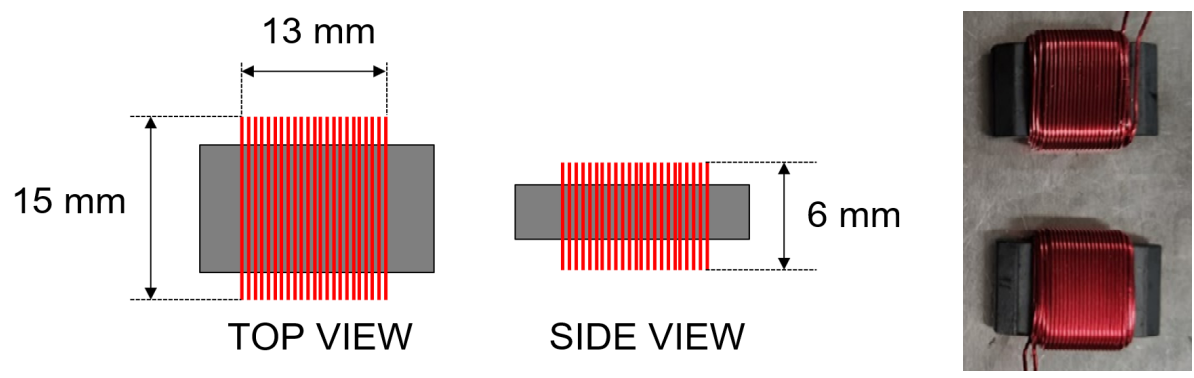

Figure 1. Diagram of designed and fabricated coil.

Table 1. Electrical characteristics of the designed coil.

\begin{tabular}{ccc}
\hline Frequency $\mathbf{( k H z )}$ & Inductance $\mathbf{L}(\boldsymbol{\mu H})$ & Quality Factor $\mathbf{Q}$ \\
\hline 1 & 301.9 & 4.195 \\
10 & 303.5 & 34.75 \\
\hline
\end{tabular}

\subsection{Metal Barrier Effect}

Figure 2 shows measured results of inductance, $L$, and resistance, $R_{S}$, of the designed coil in two different scenarios: when the coil is located on top of a nonmetallic surface (L,R-Air), and when it is located on top of a $1 \mathrm{~mm}$-thick aluminum plate (L,R-Metal). Measurements were made in the frequency range from $500 \mathrm{~Hz}$ to $10 \mathrm{kHz}$ using a passive component LCR meter (LCR200 from Extech). For the case when the coil is located on top 
of a nonmetallic surface, inductance and resistance remain fairly constant with respect to frequency, $L=300 \mu \mathrm{H}$ and $R_{s}=0.4 \Omega$. On the contrary, when the coil is located on top of the metal plate, inductance decreases $(L=216 \mu \mathrm{H})$ with frequency due to the induced opposite current on the plate that cancels the current from the coil [20]. Likewise, the resistance increases $\left(R_{s}=1.4 \Omega\right)$ because the induced current on the plate contributes to the total resistance of the coil.

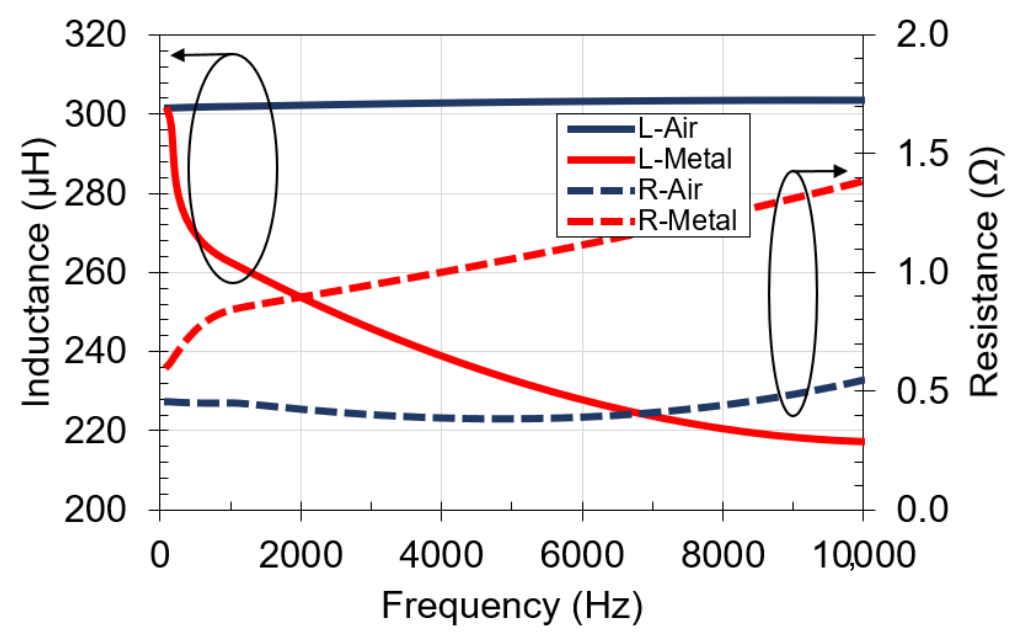

Figure 2. Measured inductance and resistance versus frequency for coil on: air and $1 \mathrm{~mm}$-thick aluminum plate.

Figure 3 shows the effect of the metal plate on mutual inductance. There is a significant decrease in mutual inductance with respect to frequency, from $80 \mu \mathrm{H}$ to $2.5 \mu \mathrm{H}$. The mutual inductance is equal to the product of self-inductance and coupling factor $k$. As the selfinductance drops with respect to frequency, the mutual-inductance also decreases as shown in Figure 3. Additionally, the skin effect from the metal plate will lower the coupling factor $k$ [21]. Thus, the mutual inductance will decrease further, limiting the upper operating frequency of the wireless power transfer system.

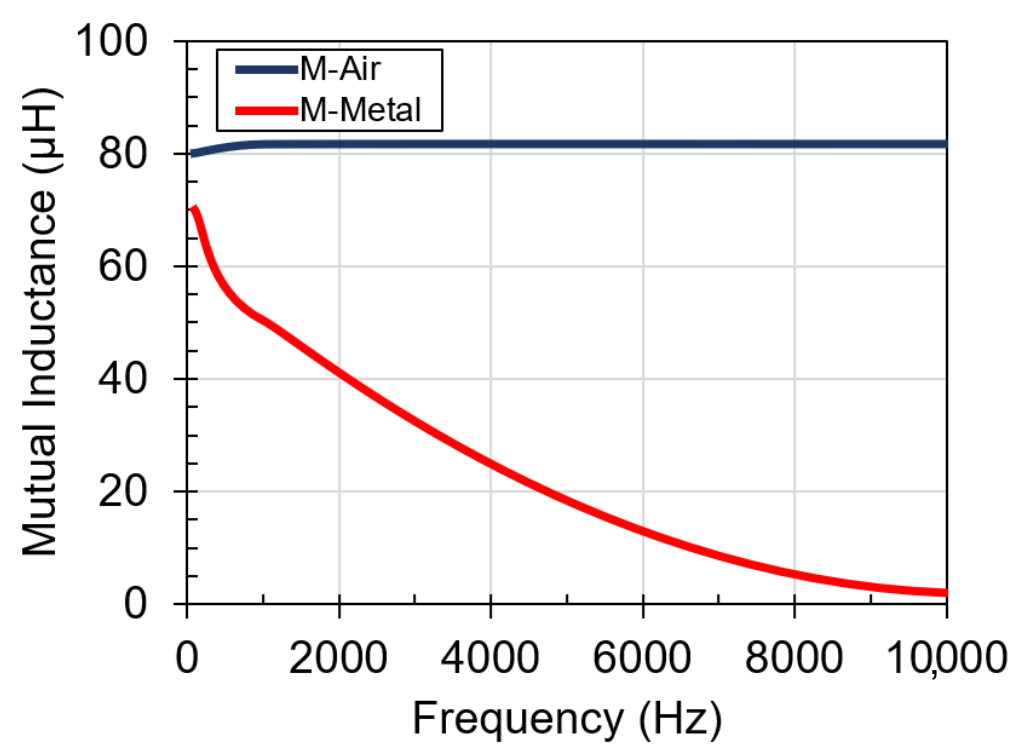

Figure 3. Mutual inductance versus frequency for coil on: air and $1 \mathrm{~mm}$-thick aluminum plate. 


\subsection{Load Effect}

The miniature coil was designed to have an input resistance of a few ohms that will allow efficient rectification and matching while providing high harvested power [22]. Figure 4 shows the circuit diagram used for measuring harvested power. Parallel capacitors, $C_{t x}=C_{r x}=24 \mu \mathrm{F}$, are used to resonate the system at $2 \mathrm{kHz}$ to maximize power transfer [23]. Load $R_{L}$ was varied in the range $1 \Omega-1 \mathrm{k} \Omega$ to find an optimal value. Figure 5 shows measured results of harvested power and received voltage for different loads. The optimal load is $4 \Omega$ and harvests $180 \mathrm{~mW}$ with $8.5 \mathrm{~W}$ of input power. As load $R_{L}$ rises, the received voltage increases while the harvested power decreases. At a $4 \Omega$ load, the harvested power peaks at $180 \mathrm{~mW}$, while the received voltage is $850 \mathrm{mV}_{\mathrm{rms}}$, which should be high enough to achieve rectifier efficiencies between $45-62 \%$ [24]. The $4 \Omega$ load provides an optimal impedance match at the output of the receiving coil.

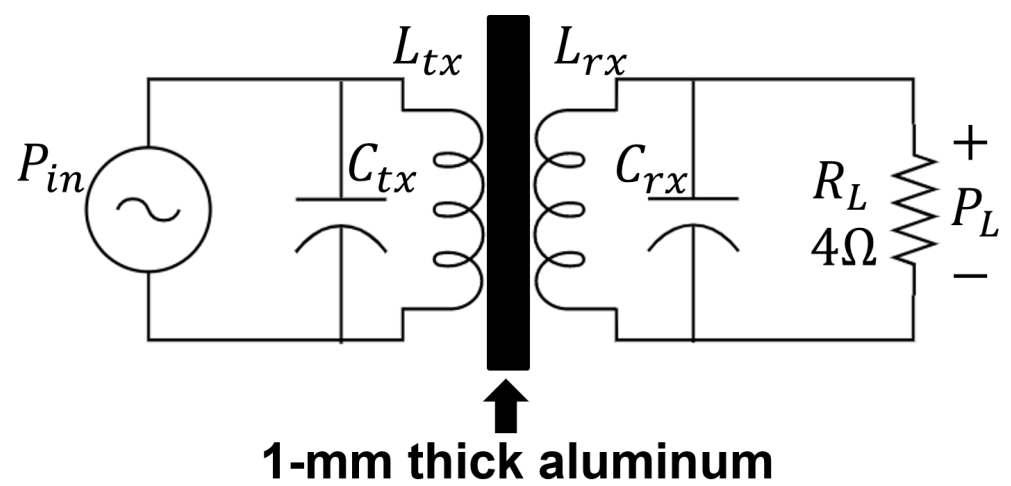

Figure 4. Circuit used to measure harvested power for the designed coil.

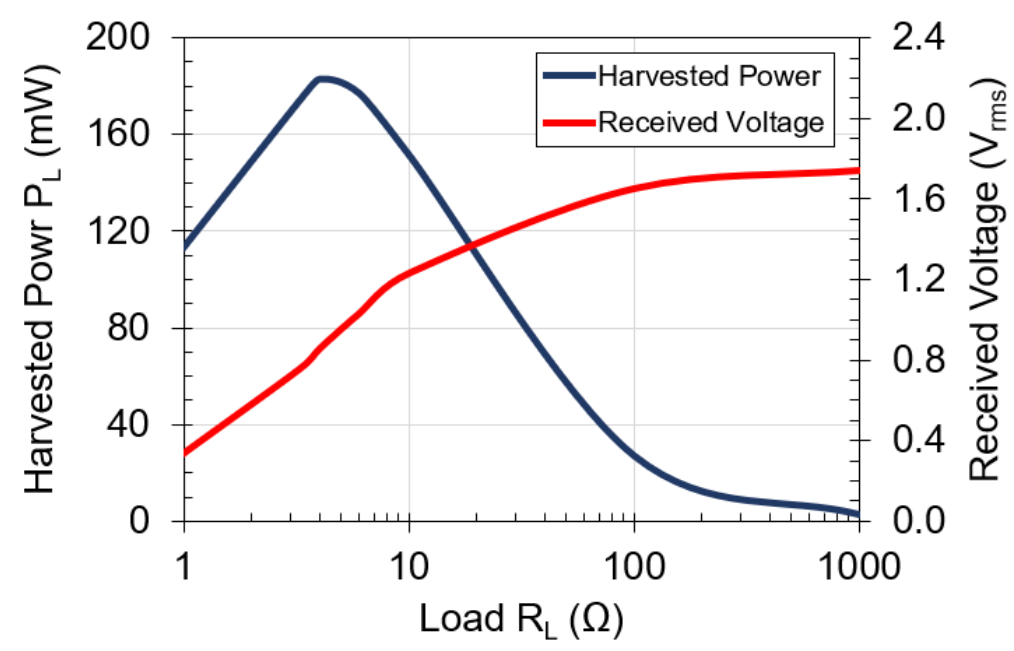

Figure 5. Harvested power and received voltage versus load for designed coil with $1 \mathrm{~mm}$-thick aluminum plate in between. Operating frequency is $2 \mathrm{kHz}$. Input power is $8.5 \mathrm{~W}$.

\subsection{Coil Performance}

Figure 4 shows the circuit diagram used to measure the performance of the designed coil. For each operating frequency, from $1-10 \mathrm{kHz}$, the values of the parallel capacitors were changed to ensure the resonance condition and harvested power was measured. Figure 6 shows measured results for harvested power and power transfer efficiency versus frequency. The maximum harvested power using this configuration is $190 \mathrm{~mW}$ at $2 \mathrm{kHz}$ with an input power of $10 \mathrm{~W}$. At $2 \mathrm{kHz}$, the parallel capacitances to create resonance are $C_{t x}=C_{r x}=24 \mu \mathrm{F}$. 


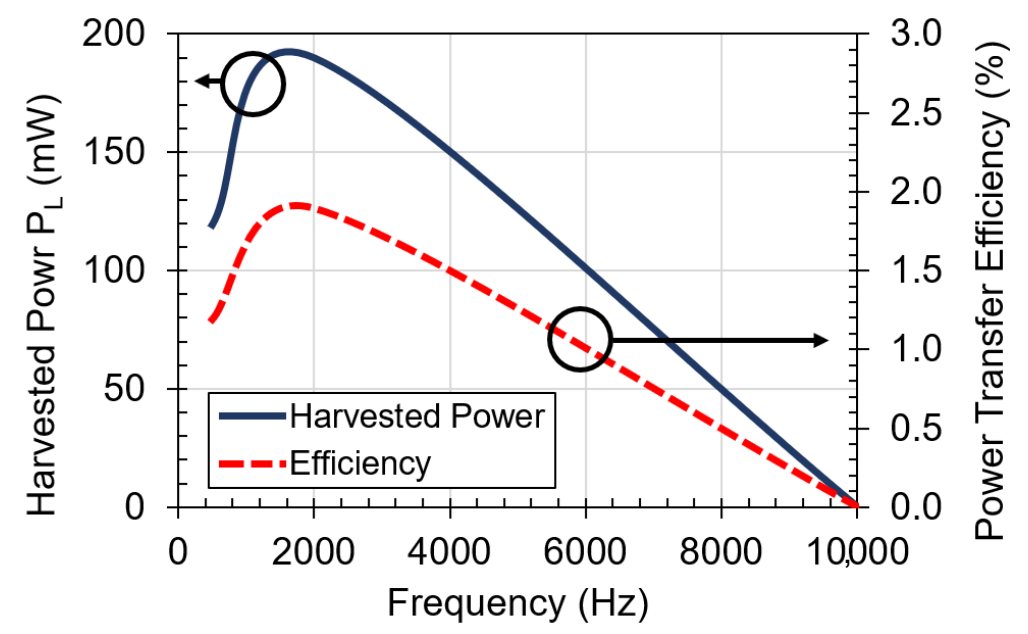

Figure 6. Measured harvested power versus frequency for designed coil with $1 \mathrm{~mm}$-thick aluminum plate in between. Input power is $10 \mathrm{~W}$.

Figure 7 shows the measured harvested power and power transfer efficiency versus input power at the optimal frequency of $2 \mathrm{kHz}$. The coil is designed to handle up to $35 \mathrm{~W}$ input power at the transmitting side so that the receiver coil can harvest up to $440 \mathrm{~mW}$. The power transfer efficiency varies from $2.5 \%$ to a minimum of $1.2 \%$ at the highest input power of $35 \mathrm{~W}$. The input power limit of $35 \mathrm{~W}$ is related to the maximum current and temperature ratings of $24 \mathrm{AWG}$ wires from the manufacture datasheet [25,26]. At $35 \mathrm{~W}$ input power, the measured temperature of the coil temperature using a thermocouple is $110^{\circ} \mathrm{C}$, which is below the rated operating temperature of $200{ }^{\circ} \mathrm{C}$ for 24 AWG wires specified by the manufacturer. The coil is separated $0.5 \mathrm{~mm}$ away from the metal plate at each side of the barrier.

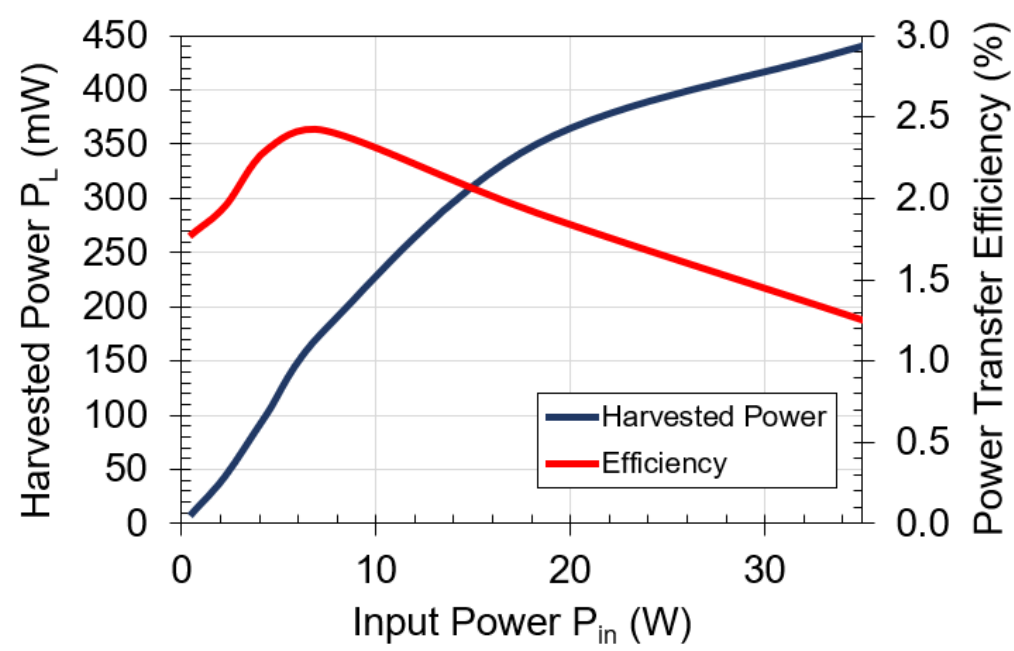

Figure 7. Measured harvested power and power transfer efficiency versus input power for the designed coil with $1 \mathrm{~mm}$-thick aluminum plate in between. Operating frequency is $2 \mathrm{kHz}$.

Table 2 shows a survey of similar works on energy transfer through aluminum and stainless steel. As seen from Table 2, coils used for through metal energy transfer are large and their volumes range from $21,205 \mathrm{~mm}^{3}$ to $3,619,114 \mathrm{~mm}^{3}$. The reported frequency of operation for through metal energy transfer is below $500 \mathrm{~Hz}$. Our frequency is much higher, at $2 \mathrm{kHz}$, and our coil size of $15 \mathrm{~mm} \times 13 \mathrm{~mm} \times 6 \mathrm{~mm}$ and volume of $1170 \mathrm{~mm}^{3}$ are the lowest. Our energy transfer per volume is $0.376 \mathrm{~mW} / \mathrm{mm}^{3}$ which is very high compared to other works. 
Table 2. Survey of similar works on energy and communications through aluminum and stainless steel.

\begin{tabular}{|c|c|c|c|c|c|c|}
\hline Reference & $\begin{array}{l}\text { Coil Size } \\
\text { (mm) }\end{array}$ & $\begin{array}{c}\text { Metal } \\
\text { Barrier } \\
\text { Thickness }\end{array}$ & $\begin{array}{l}\text { Harvested } \\
\text { Power } \\
(\mathrm{mW})\end{array}$ & $\begin{array}{c}\text { Coil Power } \\
\text { Transfer } \\
\text { Efficiency }(\%)\end{array}$ & $\begin{array}{l}\text { Frequency } \\
\quad(\mathrm{Hz})\end{array}$ & $\begin{array}{l}\text { Volume } \\
\left(\mathrm{mm}^{3}\right)\end{array}$ \\
\hline [9] & $30 \times \varnothing 30$ & $\begin{array}{c}\text { Tin } \\
0.5 \mathrm{~mm}\end{array}$ & 0.03 & - & 50 & 21,205 \\
\hline [4] & $234 \times 67 \times 30$ & $\begin{array}{l}\text { Stainless } \\
\text { steel } \\
1.6 \mathrm{~mm}\end{array}$ & 3000 & 43 & 50 & 470,340 \\
\hline [27] & $80 \times \varnothing 240$ & $\begin{array}{l}\text { Aluminum } \\
4 \mathrm{~mm}\end{array}$ & 18,181 & 23 & 100 & $3,619,114$ \\
\hline [28] & $8 \times \varnothing 115$ & $\begin{array}{l}\text { Stainless } \\
\text { Steel } \\
20 \mathrm{~mm}\end{array}$ & 7000 & 5.5 & 500 & 83,095 \\
\hline [12] & $50 \times \varnothing 98$ & $\begin{array}{l}\text { Aluminum } \\
3.1 \mathrm{~mm}\end{array}$ & 5000 & 9 & 250 & 377,148 \\
\hline $\begin{array}{l}\text { This } \\
\text { work }\end{array}$ & $15 \times 13 \times 6$ & $\begin{array}{l}\text { Aluminum } \\
1 \mathrm{~mm}\end{array}$ & 440 & 2.5 & 2000 & 1170 \\
\hline
\end{tabular}

\section{Through Metal Scenarios}

This section includes the performance of the coil, in terms of harvested power and power transfer efficiency, for different types of materials, thicknesses and frequencies. Figure 8 shows a picture of the different plates used in the experiments. Two types of alloys are used: stainless steel (AISI 304) and aluminum (6061T6). Different thicknesses of each of the plates are summarized in Table 3. In these experiments, we place one coil on each side of a plate to form an inductive link as shown in Figure 4.

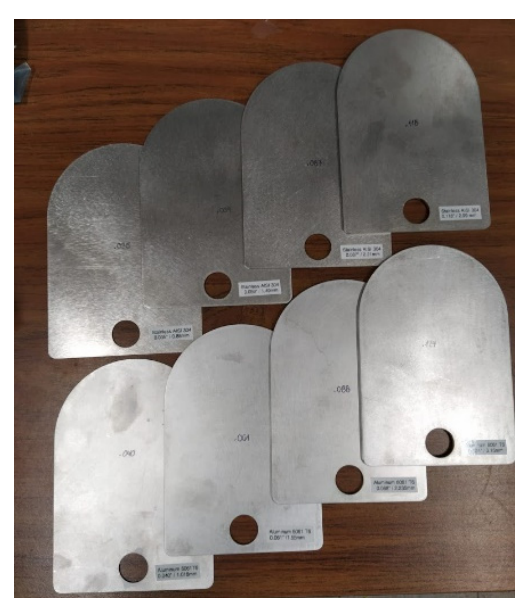

Figure 8. Plates of different materials used in the experiments.

Table 3. Plates used for the experiments.

\begin{tabular}{cc}
\hline Stainless Steel AISI 304 Thickness (mm) & Aluminum 6061T6 Thickness (mm) \\
\hline 0.88 & 1.55 \\
1.49 & 2.235 \\
2.21 & 3.15 \\
2.99 & 4.98 \\
\hline
\end{tabular}




\subsection{Stainless Steel}

Figure 9 shows the measured results of harvested power versus input power for stainless steel plates of different thicknesses. Stainless steel is a material that is less conductive than aluminum. The conductivity of stainless steel and aluminum is $1.38 \times 10^{6} \mathrm{~S} / \mathrm{m}$ and $25 \times 10^{6} \mathrm{~S} / \mathrm{m}$, respectively [29]. Hence, the skin effect is reduced and power can be transferred more effectively through stainless steel [30]. For a $0.88 \mathrm{~mm}$-thick stainless steel plate, the harvested power is almost $700 \mathrm{~mW}$. If the plate thickness is increased to $1.49 \mathrm{~mm}$, more than $400 \mathrm{~mW}$ can be harvested. When using a $2.99 \mathrm{~mm}$-thick stainless steel plate, $300 \mathrm{~mW}$ can be harvested, which is nearly double the harvested power through a $1 \mathrm{~mm}$-thick aluminum barrier.

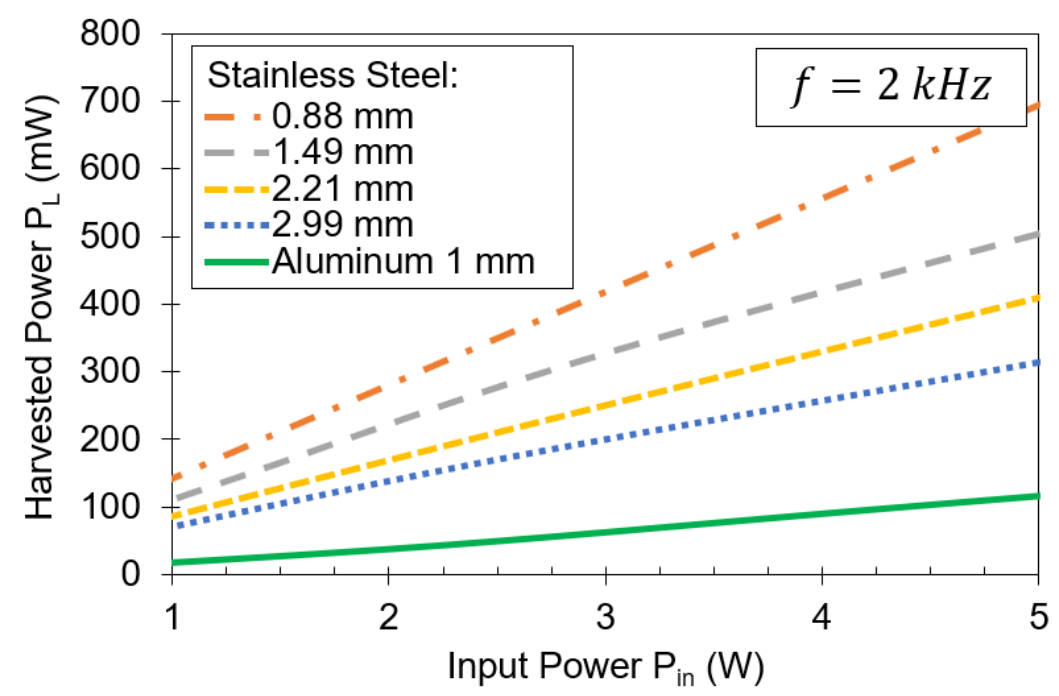

Figure 9. Harvested power versus input power using stainless steel plates of different thickness. Operating frequency is $2 \mathrm{kHz}$.

Figure 10 shows the power transfer efficiency results for the same configuration. By using stainless steel, efficiency can be tripled, even if the thickness of the plate is $2.99 \mathrm{~mm}$. Efficiency increases further with thinner plates. For stainless steel, power transfer efficiency can go from a minimum of $6 \%$ to a maximum of $14 \%$ for thicknesses from 2.99 to $0.88 \mathrm{~mm}$, respectively. Figure 10 also includes the power transfer efficiency results for aluminum plates of different thicknesses. As the aluminum plate thickness increases from 1.5 to $4.98 \mathrm{~mm}$, the efficiency decreases from results $1 \%$ to $0.04 \%$, respectively. For the thickest aluminum plate, $4.98 \mathrm{~mm}$, less than $0.04 \%$ efficiency is obtained.

The skin depth $(\delta=1 / \sqrt{\pi f \mu \sigma})$ [31] of stainless steel and aluminum at $2 \mathrm{kHz}$ is $9.57 \mathrm{~mm}$ and $2.25 \mathrm{~mm}$, respectively. Therefore, the E-field $\left(E=E_{0} e^{-d / \delta}\right)$ attenuated into the metal faster for aluminum than stainless steel. In other words, at the same distance into metal, the electric field amplitude in stainless steel is much higher than that in aluminum. As a result, harvested power through stainless steel is higher than that through aluminum for the same metal thickness.

Figure 11 describes the measured harvested power with respect to frequency at an input power of $3 \mathrm{~W}$ for stainless steel. In this experiment, the frequency of the input signal is swept from $1.5 \mathrm{kHz}$ to $2.5 \mathrm{kHz}$ while load $R_{L}=4 \Omega$ and parallel capacitances $C_{t x}$ and $C_{r x}$ are fixed at $24 \mu \mathrm{F}$. The results indicate that harvested power starts to decrease above $2 \mathrm{kHz}$ due to the skin effect of the metal plate. In addition, above $2 \mathrm{kHz}$, the circuit in Figure 4 is no longer operating at resonance. To achieve maximum harvested power, the resonance principle should be maintained [32]. 


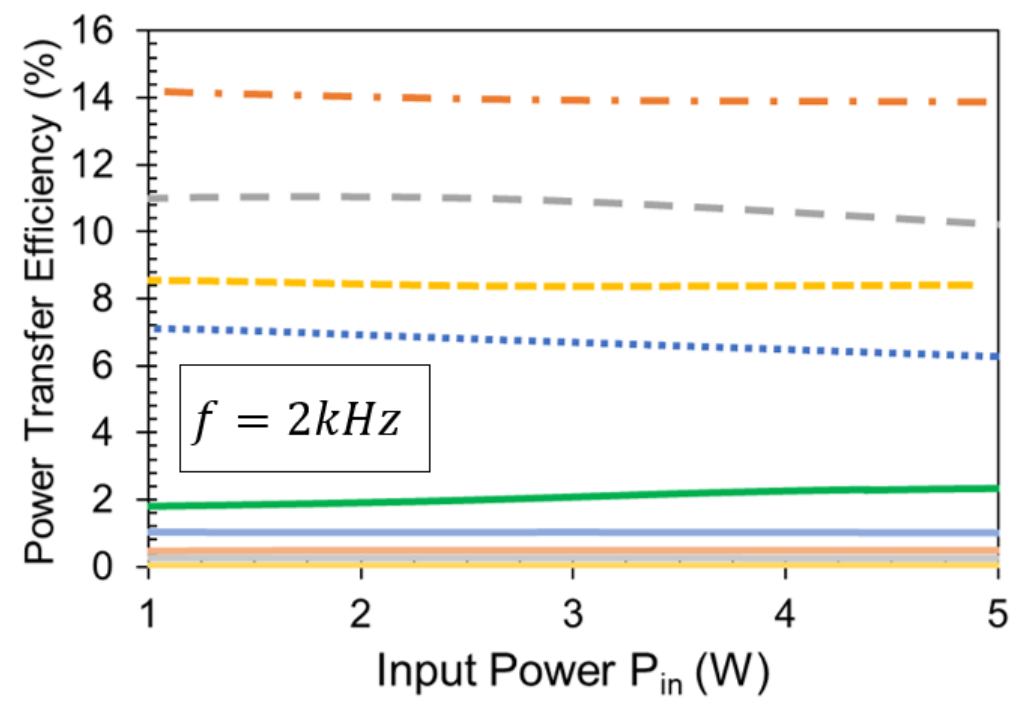

Stainless steel $(\mathrm{mm}):$
$=-0.88-=1.49--=2.21=\ldots=2.99$
Aluminum $(\mathrm{mm})$ :
$-1.55=2.235=3.150-4.98$

Figure 10. Power transfer efficiency versus input power using stainless steel and aluminum plates of different thickness. Operating frequency is $2 \mathrm{kHz}$.

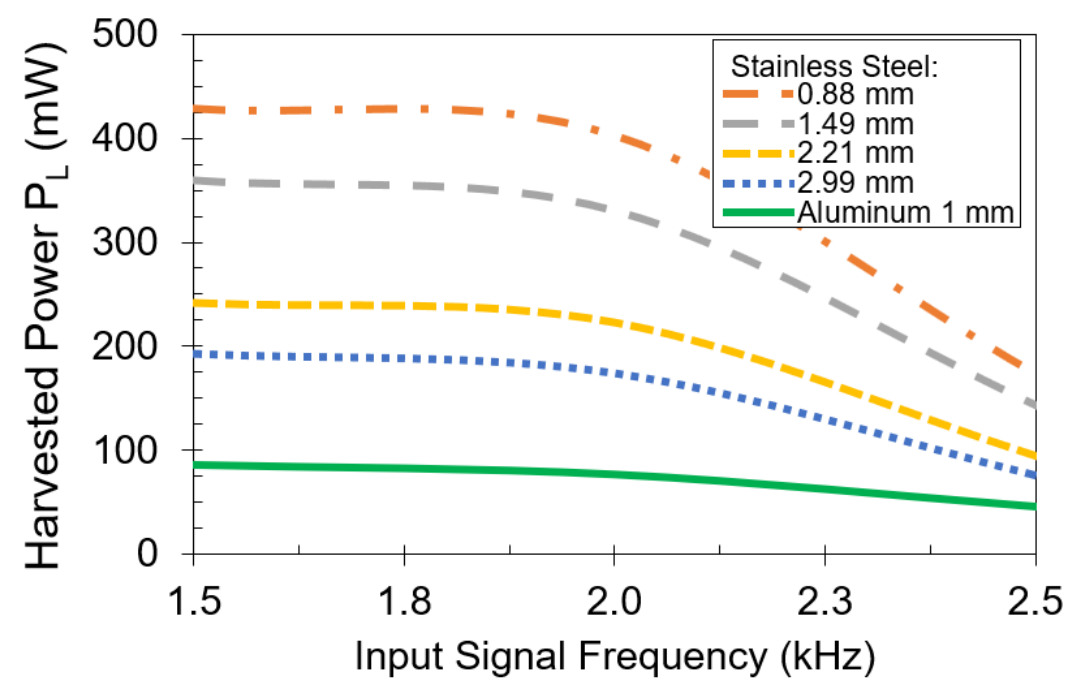

Figure 11. Harvested power versus frequency using stainless steel plates of different thicknesses. Input power is $3 \mathrm{~W}$.

Figure 12 compares the harvested power through different stainless steel plates relative to the $1 \mathrm{~mm}$-thick aluminum. The harvested power through a $2.99 \mathrm{~mm}$-thick stainless steel plate is three times more than through a $1 \mathrm{~mm}$-thick aluminum. As the thickness of the stainless steel plate decreases to $0.88 \mathrm{~mm}$, the harvested power increases 7 times more than that through $1 \mathrm{~mm}$-thick aluminum. 


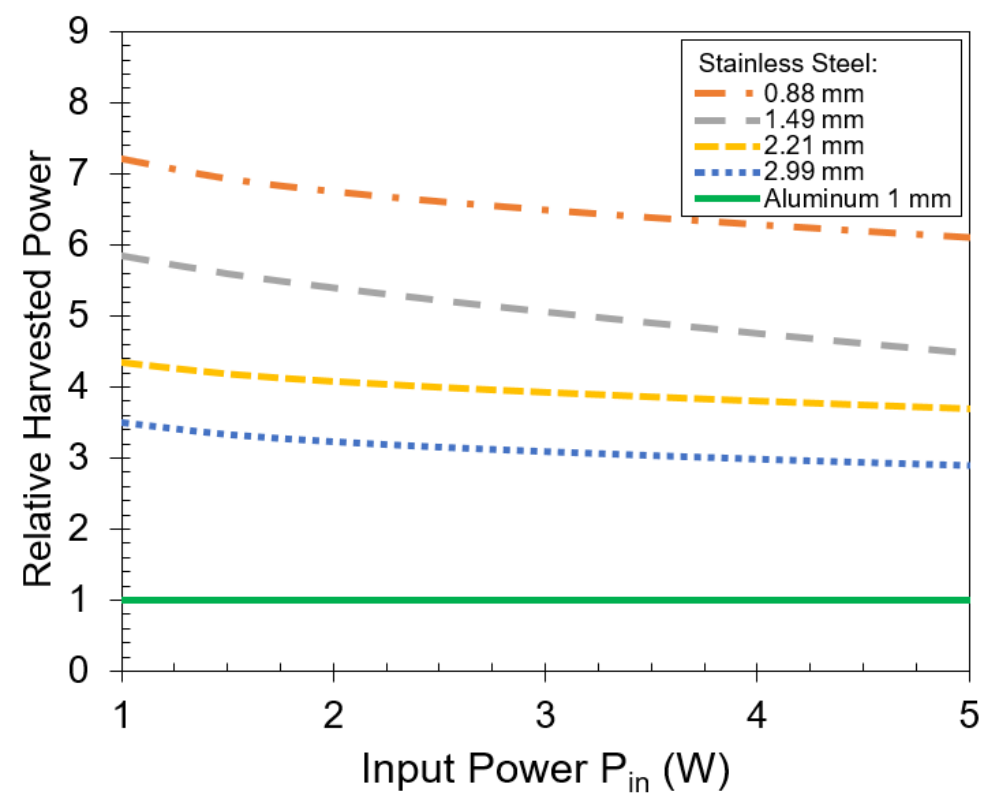

Figure 12. Relative harvested power through stainless steel plates to through a $1 \mathrm{~mm}$-thick aluminum plate versus input power. The frequency is $2 \mathrm{kHz}$.

\subsection{Aluminum}

Figure 13 shows the measured results of harvested power through aluminum plates of different thicknesses. Aluminum is more conductive than stainless steel [33], so the harvested power is considerably decreased as the thickness of the plates increases from $1 \mathrm{~mm}$. For a $1.55 \mathrm{~mm}$-thick plate, the harvested power is only $74 \mathrm{~mW}$, less than half of the harvested power using a $1 \mathrm{~mm}$-thick aluminum plate. If the plate thickness is increased to $2.235 \mathrm{~mm}, 36 \mathrm{~mW}$ are available. When the thickness is $3.15-\mathrm{mm}$, almost three times the thickness of the base line plate of 1-mm-thick aluminum, only $17 \mathrm{~mW}$ are available. Further increasing the barrier to $4.98 \mathrm{~mm}$ makes the harvested power limited to less than $3 \mathrm{~mW}$. In conclusion, stainless steel is much better than aluminum for power transfer and signal communication through it.

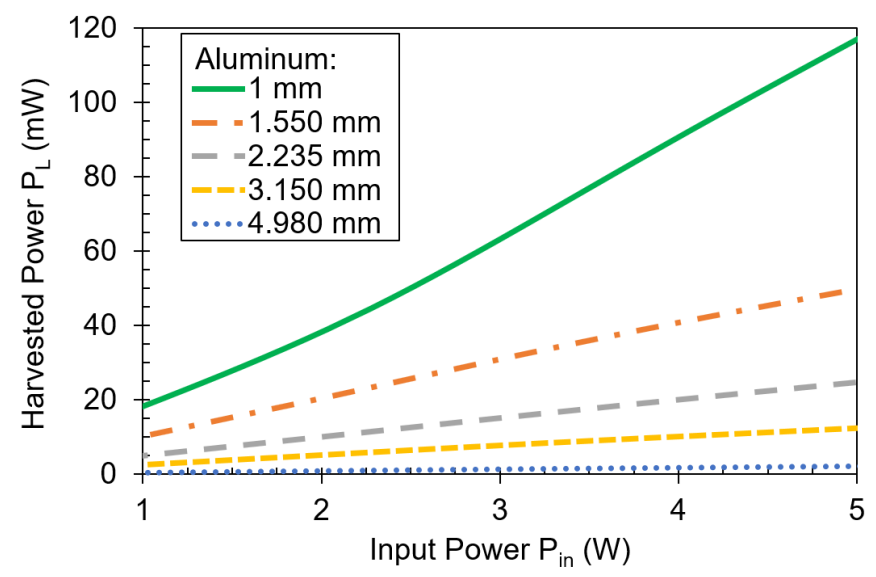

Figure 13. Harvested power versus input power using aluminum plates of different thickness. The frequency is $2 \mathrm{kHz}$.

\section{Through Metal Communication System}

Figure 14 shows the fully integrated communication system for a through metal application. Here, two distinct subsystems can be identified: outside, and inside subsystems. The outside subsystem will wirelessly transfer power to the inside subsystem through the metal plate to enable its operation. Bidirectional communication is possible using only the 
harvested power from outside. There are no batteries used inside the metal barrier. Only one pair of miniature coils is used for both energy transfer and wireless communications.

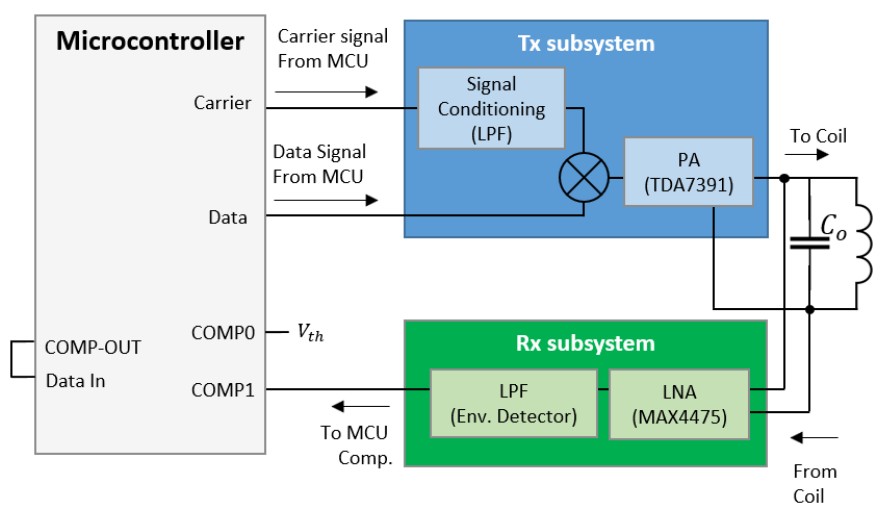

(a)

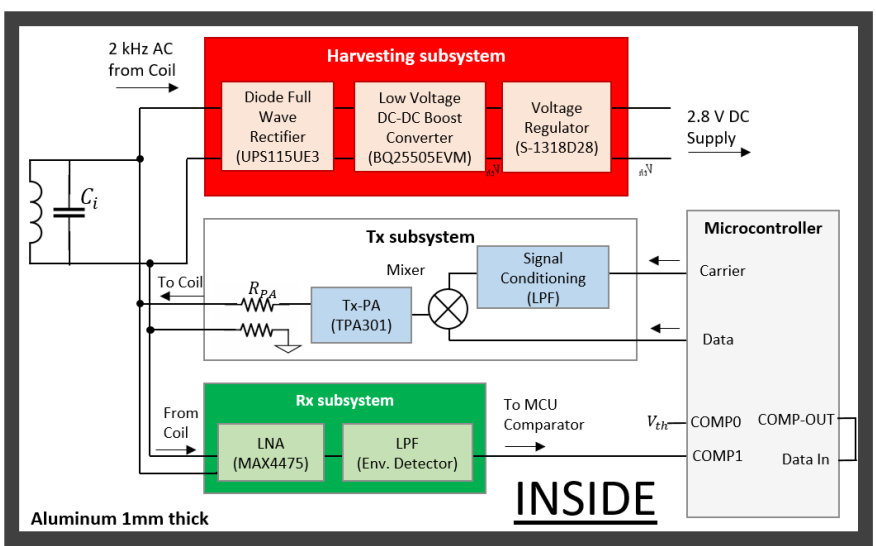

(b)

Figure 14. Fully integrated communication system: (a) outside, and (b) inside subsystem.

\subsection{Outside Subsystem}

The outside subsystem is shown in Figure 14a and is made of a Tx subsystem, Rx subsystem and microcontroller, the ATtiny 104 Xplained Nano from Microchip Technology. The Tx subsystem includes a transistor-based mixer, part number BC547 from Fairchild, and a power amplifier, part number TDA7391 from STMicroelectronics, to transmit the power and data signals through the metal plate. The Rx subsystem uses a low noise amplifier to recover the signal and an envelope detector together with a comparator for demodulation. The low noise amplifier, part number MAX4475 is from Maxim Integrated configured for gain $>400$. The envelope detector was based on a passive design, and the comparator uses the built-in module of the microcontroller. When the Tx subsystem delivers its full power in the WPT mode, the low noise amplifier is turned off to avoid overloading. In the Rx mode, the low noise amplifier is turned on while the power amplifier is off.

\subsection{Inside Subsystem}

The inside subsystem is made of a harvesting subsystem, Tx subsystem, Rx subsystem and microcontroller ATtiny104 Xplained Nano from Microchip Technology. Communication is based on amplitude shift keying (ASK) modulation due to its simplicity for wireless data transfer through metal [34]. Figure 14b shows the Tx Subsystem which consists of a low power mixer using a NPN transistor, part number BC547 from Fairchild, and the power amplifier, part number TPA301 from Texas Instruments. The Rx subsystem uses a low noise amplifier, part number MAX4475 from Maxim Integrated, a passive envelope detector, and the built-in comparator module of the microcontroller for demodulation.

Figure $14 \mathrm{~b}$ shows the harvesting subsystem used to rectify and regulate the harvested AC power from outside to supply DC power for the operation of the inside subsystem. The harvesting subsystem consists of a Schottky diode full wave rectifier, UPS115UE3 from Microchip Technology, to convert the AC harvested signal to DC. Using this full wave rectifier, the total forward voltage drop is $V_{F}<0.2 \mathrm{~V}$. The voltage at the output of the rectifier is only $1 \mathrm{~V}_{\mathrm{rms}}$ and needs to be upscaled to at least $4 \mathrm{~V}_{\mathrm{rms}}$ to charge the storage capacitor and supply power to the inside subsystem. To boost the voltage, a low-voltage boost converter, BQ25505 from Texas Instruments, was used. The boost converter has efficiency of $>80 \%$. Finally, a voltage regulator, S-1318D28 from ABLIC, was used to supply a constant $2.8 \mathrm{~V}$ supply for the inside communication subsystem for operation. The voltage regulator has a current consumption $I_{s s}<100 \mathrm{nA}$.

Figure 15 shows the input impedance $Z_{\text {in }}$ seen by the inside coil. Impedance $Z_{\text {in }}$ has an important effect in received voltage, rectifier efficiency and harvested power [35]. To 
measure received voltage, rectifier efficiency and harvested power, the outside transmitted power, $P_{T x}$, was fixed to $35 \mathrm{~W}$ at $2 \mathrm{kHz}$. The coil setup was the same for the rest of this paper, and the barrier is a $1 \mathrm{~mm}$-thick aluminum plate. Additionally, the load $R_{D C}$ on the inside subsystem was modified in the range of 10-1200 $\Omega$ to change equivalent input impedance $Z_{i n}$. The impedance $Z_{i n}$ was calculated by measuring the voltage and current at the input of the full wave rectifier.

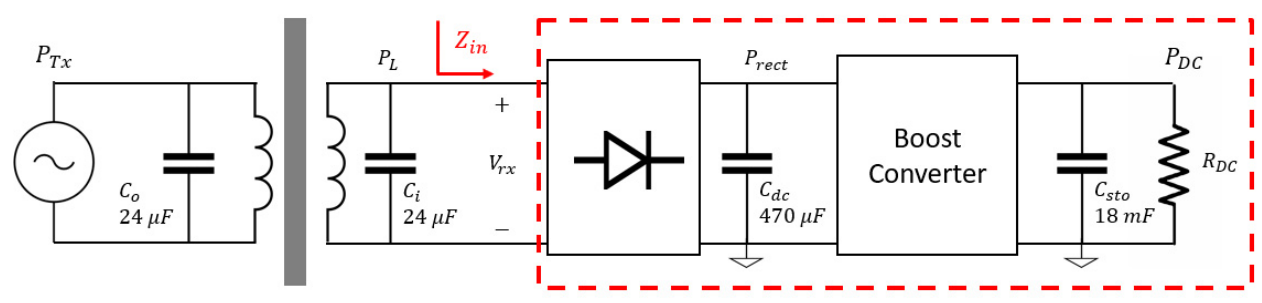

Figure 15. Complete schematic of harvesting subsystem.

Figure 16 shows the harvested AC and DC power and total rectifier efficiency versus equivalent input impedance $Z_{i n}$. When the equivalent input impedance $Z_{i n}$ is between 1-10 $\Omega$, the harvested AC power ranges from $200-356 \mathrm{~mW}$ with a peak of $440 \mathrm{~mW}$ at $4 \Omega$. In the same impedance range, the total rectifier efficiency is between $6 \%$ to $21 \%$ due to the low received voltages, typically $V_{r x}=0.5 V_{r m s}$. As a result, the harvested DC power goes from $6 \mathrm{~mW}$ to a maximum of $75 \mathrm{~mW}$ at $10 \Omega$. Input impedance $Z_{i n}=10 \Omega$ is the optimal value that provides a balance in rectifier efficiency and $A C$ harvested power. When input impedance increases further, $Z_{i n} \geq 10 \Omega$, the total rectifier efficiency increases to almost $25 \%$ while the AC harvested power degrades rapidly. Hence, when $Z_{\text {in }} \geq 10 \Omega$, the DC harvested power is reduced to $1 \mathrm{~mW}$.

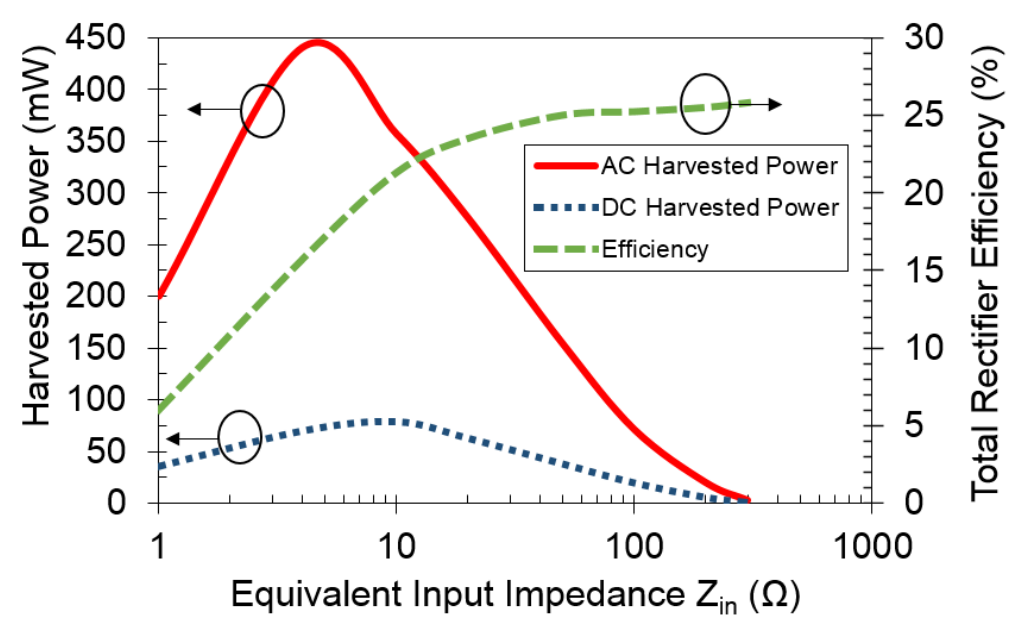

Figure 16. Measured harvested AC and DC power and total efficiency versus equivalent input impedance $Z_{i n}$.

\subsection{Prototype}

The built prototypes for the outside and inside subsystems are shown in Figure 17. A communication protocol for this specific application was designed to enable automatic power transfer to the inside subsystem and bidirectionally data communications using one pair of coils. Four different operation modes were defined: Wireless Power Transfer (WPT), $\mathrm{Tx}, \mathrm{Rx}$ and Sleep. The operation of the system is as follows: 


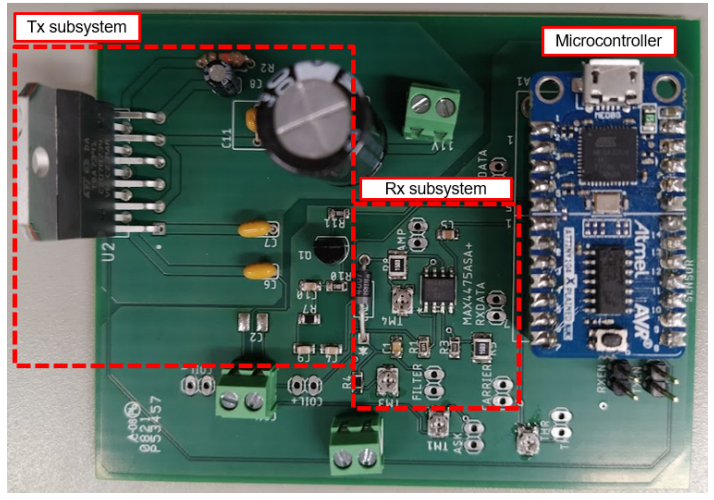

(a)

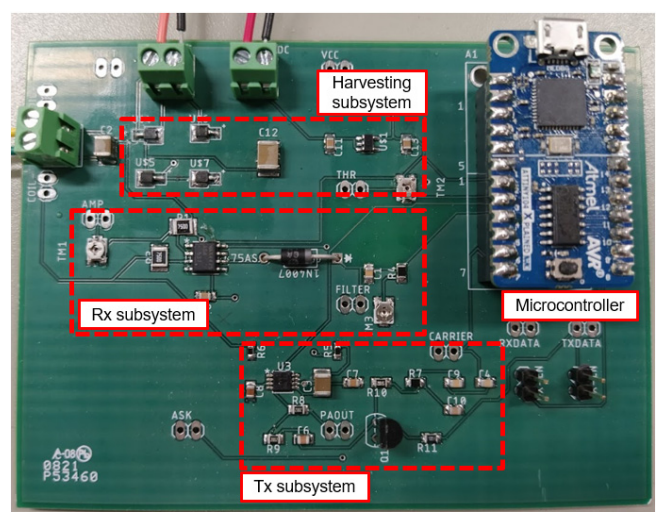

(b)

Figure 17. Built prototypes for wireless power transfer through metal communication system: (a) outside, and (b) inside subsystems.

1. Outside subsystem enters WPT mode, and transmits a high-power signal to charge the inside subsystem through the $1 \mathrm{~mm}$-thick aluminum plate.

2. Inside subsystem harvests energy. If enough power is available, it enters Rx mode and waits for an incoming data stream from the outside subsystem, otherwise toggles between Sleep and Rx modes.

3. Outside subsystem finishes its WPT mode and power transfer stops. Then, Tx mode begins and the outside subsystem transmits a data frame at a data rate of $100 \mathrm{bps}$.

4. Inside subsystem is in Rx Mode and demodulates the incoming data. If data is received correctly, the inside subsystem enters Tx mode.

5. Inside subsystem transmits data frame and goes back to Rx mode.

6. Outside subsystem is in Rx mode. The data is received and demodulated.

7. System is ready to start the cycle again.

Using this configuration, the outside subsystem transmits a power signal with a $P_{t x}=35 \mathrm{~W}$ during $7 \mathrm{~s}$ to fully charge the inside subsystem. Then, power transfer stops and data are transmitted. At the inside subsystem, the receiver demodulates the incoming data and operates during $1 \mathrm{~s}$ with a power consumption of $19 \mathrm{~mW}$. Then, it transmits data to the outside subsystem during $1 \mathrm{~s}$ with a power consumption of $39 \mathrm{~mW}$. The inside subsystem consumes $240 \mu \mathrm{W}$ in Sleep mode, $19 \mathrm{~mW}$ in Rx Mode, and $39 \mathrm{~mW}$ in Tx Mode. Using only the harvested power from outside, the inside subsystem can transmit and receive data for more than $2 \mathrm{~s}$.

\subsection{Experimental Validation}

To validate our system, bidirectional communication was tested using the designed prototypes and a pair of coils. Each coil was located and aligned on each side of a $500 \mathrm{~mm} \times 500 \mathrm{~mm} \times 1 \mathrm{~mm}$ aluminum plate. The test setup is shown in Figure 18 .

Using the previously described protocol, communication began at the outside subsystem with a push of a button of the microcontroller. Then, the wireless power transfer signal, $P_{t x}=35 \mathrm{~W}$, and data signal, $100 \mathrm{bps}$, were transmitted through the metal plate. The inside subsystem automatically harvested the power, processed the incoming data and transmitted a response. The outside subsystem processed the data and a LED lights up indicating the successful data reception. Using this procedure, successful communication outside-inside and inside-outside was confirmed. The system operated using only the harvested power through the metal plate. 


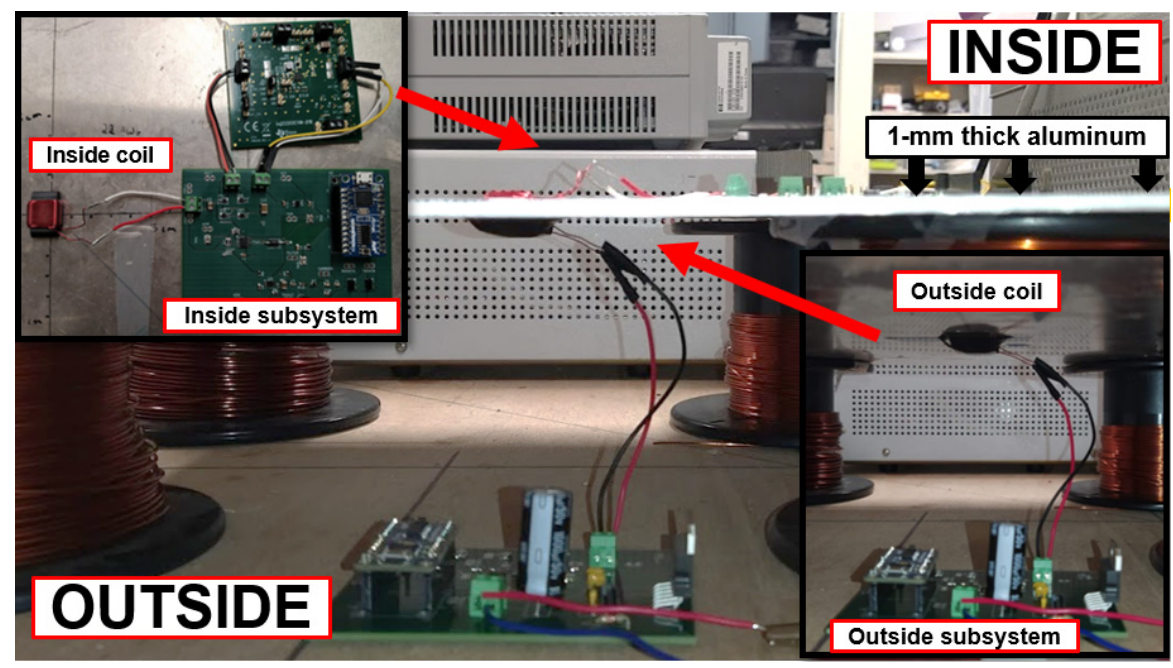

Figure 18. Test setup for through metal communication system. Below the metal plate: the coil connected to the outside subsystem. Above the metal plate: the coil and the inside subsystem. Each coil is located at the center of the $1 \mathrm{~mm}$-thick aluminum plate and separated $0.5 \mathrm{~mm}$ away from the metal plate.

For further validation, a sample of inside to outside data transfer is presented in Figure 19. The transmit data corresponds to the digital output of the microcontroller of the inside subsystem, and the receive data is the demodulated data at the output of the outside subsystem. Communication is successful at a data rate of $100 \mathrm{bps}$ using a $2 \mathrm{kHz}$ carrier. A bit error rate analysis (BER) was calculated for the data transmission through metal using 360,000 bits during a time period of $60 \mathrm{~min}$ of data transmission. The results showed that the BER $<1 \times 10^{-6}$ for the wireless power transfer data link through metal.

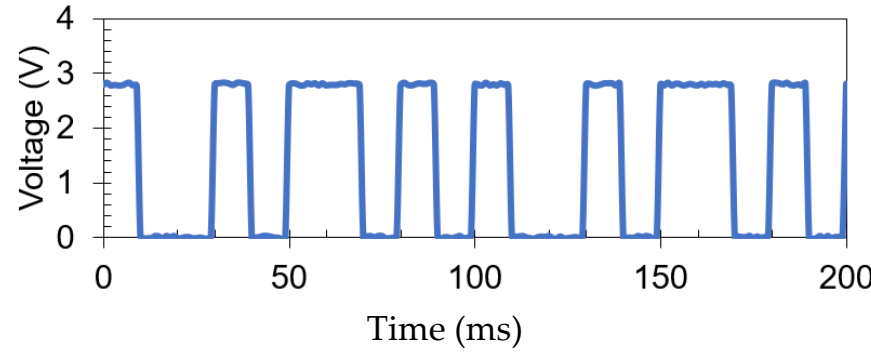

(a)

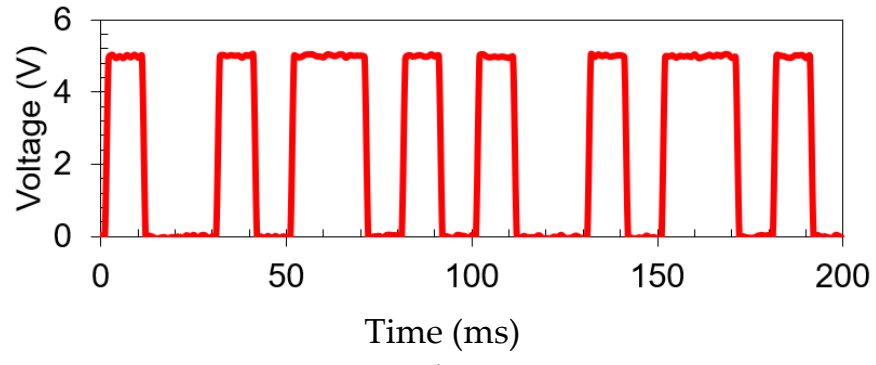

(b)

Figure 19. Transmit (a) and receive (b) data signal at 100 bps using a $2 \mathrm{kHz}$ carrier.

\section{Conclusions}

This paper presents the first demonstration of power and data transfer through metal using a miniature coil. The system can operate through a $1 \mathrm{~mm}$-thick aluminum plate using a coil of very small size, only $15 \mathrm{~mm} \times 13 \mathrm{~mm} \times 6 \mathrm{~mm}$. The maximum coil-to-coil power transfer efficiency is $2.4 \%$, and the maximum harvested power is $440 \mathrm{~mW}$ operating at $2 \mathrm{kHz}$. Additionally, the designed coil can harvest power in a variety of materials of different thicknesses. Harvested power is more than $10 \mathrm{~mW}$ through a $4.98 \mathrm{~mm}$-thick aluminum plate, and more than $4.5 \mathrm{~W}$ through a $0.88 \mathrm{~mm}$-thick stainless steel plate.

Author Contributions: Conceptualization, A.-V.P. and C.S.G.; methodology, J.M.R.-A. and A.-V.P.; software, J.M.R.-A.; validation, J.M.R.-A. and A.-V.P.; formal analysis, J.M.R.-A. and A.-V.P.; investigation, J.M.R.-A.; resources, C.S.G. and B.T.F.; data curation, J.M.R.-A.; writing-original draft preparation, J.M.R.-A.; writing-review and editing, J.M.R.-A., A.-V.P. and B.T.F.; visualization, B.T.F.; supervision, A.-V.P., B.T.F. and C.S.G.; project administration, B.T.F. and C.S.G.; funding acquisition, A.-V.P., B.T.F. and C.S.G. All authors have read and agreed to the published version of the manuscript. 
Funding: This research was funded by Lawrence Livermore National Laboratory grant number B638423.

Institutional Review Board Statement: Not applicable.

Informed Consent Statement: Not applicable.

Data Availability Statement: The data presented in this study is available from the corresponding author upon reasonable request.

Conflicts of Interest: The authors declare no conflict of interest.

\section{References}

1. Xie, L.; Shi, Y.; Hou, Y.T.; Lou, A. Wireless power transfer and applications to sensor networks. IEEE Wirel. Commun. 2013, 20, 140-145.

2. Yang, D.X.; Hu, Z.; Zhao, H.; Hu, H.F.; Sun, Y.Z.; Hou, B.Y. Through-metal-wall power delivery and data transmission for enclosed sensors: A review. Sensors 2015, 15, 31581-31605. [CrossRef] [PubMed]

3. Torres, O.; Nguyen, T.; Mackenzie, A. Enabling Wireless Avionics Intra-Communications; NASA: Hampton, VA, USA, December 2016.

4. Yamakawa, M.; Mizuno, Y.; Ishida, J.; Komurasaki, K.; Koizumi, H. Wireless power transmission into a space enclosed by metal walls using magnetic resonance coupling. Wirel. Eng. Technol. 2014, 5, 19-24. [CrossRef]

5. Vu, T.A.; Pham, C.V.; Tran, W.; Pham, A.V.; Gardner, C.S. Wireless power and data transfer through carbon composite using a common inductive link. Int. J. Power Electron. Drive Syst. (IJPEDS) 2020, 3, 1441-1448. [CrossRef]

6. Alhamrouni, I.; Iskandar, M.; Salem, M.; Awalin, L.J.; Jusoh, A.; Sutikno, T. Application of inductive coupling for wireless power transfer. Int. J. Power Electron. Drive Syst. (IJPEDS) 2020, 11, 1109. [CrossRef]

7. Jeong, N.S.; Carobolante, F. Enabling wireless power transfer though a metal encased handheld device. In Proceedings of the 2016 IEEE Wireless Power Transfer Conference (WPTC), Aveiro, Portugal, 5-6 May 2016.

8. Jeong, N.S.; Carobolante, F. Wireless charging of a metal-body device. IEEE Trans. Microw. Theory Tech. 2017, 65, 1077-1086. [CrossRef]

9. Zangl, H.; Fuchs, A.; Bretterklieber, T.; Moser, M.J.; Holler, G. Wireless Communication and Power Supply Strategy for Sensor Applications Within Closed Metal Walls. IEEE Trans. Instrum. Meas. 2020, 59, 1686-1692. [CrossRef]

10. Pham, C.V.; Pham, A.V.; Gardner, C.S. Development of Helical circular coils for wireless through-metal inductive power transfer. In Proceedings of the 2017 IEEE Wireless Power Transfer Conference (WPTC), Taipei, Taiwan, 10-12 May 2017.

11. Pham, C.V.; Vu, T.A.; Tran, W.; Pham, A.V.; Gardner, C.S. Wireless Energy Harvesting System Through Metal for Aerospace Sensor. In Proceedings of the 2018 IEEE Transportation Electrification Conference and Expo (ITEC), Long Beach, CA, USA, 13-15 June 2018.

12. Vu, T.A.; Pham, C.V.; Pham, A.V.; Gardner, C.S. Wireless power transfer through metal using inductive link. Int. J. Power Electron. Drive Syst. (IJPEDS) 2019, 10, 1906-1913. [CrossRef]

13. Zhou, W.; Su, Y.; Huang, L.; Qing, X.; Hu, A.P. Wireless Power Transfer Across a Metal Barrier by Combined Capacitive and Inductive Coupling. IEEE Trans. Ind. Electron. 2019, 66, 4031-4041. [CrossRef]

14. Jawad, A.M.; Nordin, R.; Gharghan, S.K.; Jawad, H.M.; Ismail, M. Opportunities and challenges for near-field wireless power transfer: A review. Energies 2017, 10, 1022. [CrossRef]

15. Romero-Arguello, J.M.; Pham, A.V.; Gardner, C.S.; Funsten, B. Miniature Coil Design for Through Metal Wireless Power Transfer. In Proceedings of the 2021 IEEE Wireless Power Transfer Conference (WPTC), San Diego, CA, USA, 1-4 June 2021.

16. Liu, X.; Xia, C.; Yuan, X. Study of the circular flat spiral coil structure effect on wireless power transfer system performance. Energies 2018, 11, 2875. [CrossRef]

17. Wang, M.; Feng, J.; Shi, Y.; Shen, M. Demagnetization weakening and magnetic field concentration with ferrite core characterization for efficient wireless power transfer. IEEE Trans. Ind. Electron. 2018, 66, 1842-1851. [CrossRef]

18. Babatunde, O.; Partridge, J.; Bucknall, R. Finite Element Modeling and Analysis of High Power, Low-loss Flux-Pipe Resonant Coils for Static Bidirectional Wireless Power Transfer. Energies 2019, 12, 3534.

19. 43 Material Data Sheet. Available online: https://www.fair-rite.com/43-material-data-sheet/ (accessed on 19 October 2021).

20. Li, J.; Huang, X.; Chen, C.; Tan, L.; Wang, W.; Guo, J. Effect of metal shielding on a wireless power transfer system. AIP Adv. 2017, 7, 056675. [CrossRef]

21. Allamehzadeh, H. Wireless Power Transfer (WPT) Fundamentals with Resonant Frequency-Dependent Parameters, Energy Transfer Efficiency, and Green Technology Applications. In Proceedings of the 2021 IEEE 48th Photovoltaic Specialists Conference (PVSC), Lauderdale, FL, USA, 20-25 June 2021.

22. Chen, Y.S.; Chiu, C.W. Theoretical limits of rectifying efficiency for low-power wireless power transfer. Int. J. RF Microw. Comput.-Aided Eng. 2018, 28, e21218. [CrossRef]

23. Jiang, C.; Chau, K.T.; Liu, C.; Lee, C.H. An overview of resonant circuits for wireless power transfer. Energies 2017, $10,894$. [CrossRef] 
24. Noghabaei, S.M.; Radin, R.L.; Savaria, Y.; Sawan, M. A high-efficiency ultra-low-power CMOS rectifier for RF energy harvesting applications. In Proceedings of the 2018 IEEE International Symposium on Circuits and Systems (ISCAS), Florence, Italy, 27-30 May 2018.

25. Wire Gauge and Current Limits Including Skin Depth and Strength. Available online: https://www.powerstream.com/Wire_ Size.htm (accessed on 8 November 2021).

26. Magnet Wire, 200C, 24 AWG Polyamideimide. Available online: https://www.remingtonindustries.com/magnet-wire/magnetwire-200c-24-awg-polyamideimide-7-spool-sizes / (accessed on 8 November 2021).

27. Graham, D.J.; Neasham, J.A.; Sharif, B.S. Investigation of Methods for Data Communication and Power Delivery Through Metals. IEEE Trans. Ind. Electron. 2011, 58, 4972-4980. [CrossRef]

28. Imoru, O.; Jassal, A.; Polinder, H.; Nieuwkoop, E.; Tsado, J.; Jimoh, A.A. An Inductive Power Transfer through metal object. In Proceedings of the 2013 1st International Future Energy Electronics Conference (IFEEC), Tainan City, Taiwan, 3-6 November 2013.

29. Mitchell, B.S. Appendix 8: Electrical Conductivity of Selected Materials. In An Introduction to Materials Engineering and Science for Chemical and Materials Engineers; John Wiley \& Sons: Hoboken, NJ, USA, 2004; pp. 893-894.

30. Chung, D.D. Materials for electromagnetic interference shielding. Mater. Chem. Phys. 2020, 255, 123587. [CrossRef]

31. Inan, U.; Inan, A. Plane Waves in Lossy Media. In Electromagnetics Waves; Prentice Hall: Upper Saddle River, NJ, USA, 1999; pp. $38-55$.

32. Hui, S.Y.R. Magnetic Resonance for Wireless Power Transfer. IEEE Power Electron. Mag. 2016, 3, 14-31. [CrossRef]

33. Starrett, C.E.; Perriot, R.; Shaffer, N.R.; Nelson, T.; Collins, L.A.; Ticknor, C. Tabular electrical conductivity for aluminium. Contrib. Plasma Phys. 2020, 60, e201900123. [CrossRef]

34. Middlestead, R.W. Amplitude shift keying modulation, demodulation, and performance. In Digital Communications with Emphasis on Data Modems: Theory, Analysis, Design, Simulation, Testing, and Applications; Wiley: Hoboken, NJ, USA, 2017; pp. 227-250.

35. Huang, Y.; Shinohara, N.; Mitani, T. Impedance matching in wireless power transfer. IEEE Trans. Microw. Theory Tech. 2016, 65, 582-590. [CrossRef] 